\title{
A PRÁTICA EDUCATIVA DO PROFESSOR DE GEOGRAFIA COMO FERRAMENTA PARA A CONSTITUIÇÃO DA CONSCIÊNCIA CIDADÃ
}

\section{THE EDUCATIONAL PRACTICE OF THE GEOGRAPHY TEACHER AS A TOOL FOR THE CONSTITUTION OF CITIZENCONSCIOUSNESS}

\author{
LA PRÁTICA EDUCATIVA DEL PROFESSOR DE GEOGRAFÍA COMO \\ HERRAMIENTA PARA LA CONSTITUCIÓN DE LA CONCIENCIA CIUDADANA
}

Elvis Reis de Oliveira ${ }^{1}$ http://orcid.org/0000-0002-8129-4770

Renata Silva Jorge ${ }^{2}$ https://orcid.org/0000-0003-1351-5110

\footnotetext{
${ }^{1}$ Mestre em Geografia - Universidade Federal do Espírito Santos. Professor da Prefeitura Municipal de Serra-ES. E-mail: elvisgeoufes@gmail.com

${ }^{2}$ Mestra em Educação Física - Universidade Federal do Espírito Santos. Professora Substituta da Universidade Federal do Tocantins. E-mail: renatasjmax@hotmail.com
}

\begin{abstract}
RESUMO
O objetivo deste trabalho é investigar a prática educativa como ferramenta para o processo de ensino e aprendizagem da Geografia Escolar, por meio da perspectiva da Educação Geográfica como um aparato que permite considerar a realidade do aluno. A pesquisa foi realizada junto de duas professoras da rede municipal da cidade de Cariacica - ES, na qual se constitui um estudo de análise do cotidiano, das práticas educativas e das narrativas dos professores de Geografia do Ensino Fundamental. Para a realização dessas análises, foi necessário categorizar as observações das aulas e as informações presentes nas entrevistas, tais como: a) a perspectiva pedagógica da problematização do conteúdo e a dialogicidade; b) a abordagem de conteúdo em torno da formação da consciência espacial cidadã, c) o processo de ensino e aprendizagem na conscientização espacial. Através das análises dos dados, chega-se à conclusão de que existe uma intencionalidade por parte das professoras entrevistadas, que aparece com mais clareza na concepção de Geografia Escolar e na Perspectiva Pedagógica.
\end{abstract}

Palavras-chave: Prática de ensino; Educação geográfica; Consciência espacial cidadã.

\begin{abstract}
This work aims to highlight the educational practice as a tool for the teaching process and learning of school geography, from the perspective of Geographic Education, as a practice that allows considering the reality of the student. The research was carried out with two teachers from the municipal network of the city of Cariacica - ES. The study is constituted in an analysis of daily life and practices, and in the narratives of teachers of Geography of Elementary School. To perform the analyses it was necessary to categorize the observations of the classes and the information present in the interviews: a)
\end{abstract}


the pedagogical perspective of the problematization of the content and the dialog city; b) the content approach around the formation of citizen spatial awareness; c) and the teaching and learning process in spatial awareness. Through data analysis, it is concluded that there is intentionality on the part of the interviewed teachers. Such intentionality appears, more clearly, in the conception of School Geography and in the Pedagogical Perspective.

Keywords: Teaching Practice; Geographic Education; Citizen spatial awareness.

\section{RESUMEN}

El objetivo de este trabajo es investigar la práctica educativa como herramienta para el proceso de enseñanza y aprendizaje de la Geografía Escolar, a través de la perspectiva de la Educación Geográfica como un aparato que permite considerar la realidad del alumno. La investigación se realizó con dos docentes de la red municipal de la ciudad de Cariacica - ES, lo que constituye un estudio del análisis de la vida cotidiana, prácticas educativas y narrativas de los docentes de Geografía en Educación Primaria. Para realizar estos análisis, fue necesario categorizar las observaciones de las clases y la información presente en las entrevistas, tales como: a) la perspectiva pedagógica de problematizar el contenido y la dialogicidad; b) el enfoque de contenidos en torno a la formación de la conciencia espacial ciudadana, c) el proceso de enseñanza y aprendizaje en la conciencia espacial. Através del análisis de datos, se concluye que existe una intención por parte de los docentes entrevistados, que aparece más claramente en el concepto de Geografía Escolar y en la Perspectiva Pedagógica.

Palabras clave: Práctica docente; Educación geográfica; Conciencia espacial ciudadana.

\section{INTRODUÇÃO}

O presente estudo insere-se no campo de pesquisa que investiga as práticas e os saberes na educação escolar, estabelecendo como foco o ensino da Geografia. Esta análise é de fundamental importância, pois permite uma reflexão sobre o processo de ensino e aprendizagem. Tais pesquisas permitem tornar mais claros os pressupostos teóricos metodológicos que orientam a prática dos professores na atualidade.

Assim, o objetivo deste trabalho é investigar a prática educativa como alternativa para o processo de ensino e aprendizagem, a partir da perspectiva da Educação Geográfica como uma prática que permite levar em consideração a realidade do aluno. Dessa forma, a prática educativa é considerada um pressuposto para as análises e observações de campo de duas professoras, que buscam identificar nas práticas educativas suas intenções e finalidades em relação à formação da consciência espacial-cidadã.

Os estudos e análises das práticas e falas dos professores de Geografia, no âmbito da construção da consciência espacial e cidadã de seus alunos, constituem-se a partir de algumas constatações e inquietações que surgem na contemporaneidade. 
A prática educativa do professor de geografia como ferramenta para a constituição da consciência cidadã

É válido ressaltar que muitas vezes os desencontros na fala e na prática do docente é fruto de uma ausência de comunicação entre a academia e a escola, o que faz com que a Geografia Escolar se mantenha "congelada e mumificada, praticamente alheia à renovação e mandamento" (SPEGIORIN, 2007, p.23).

Esse processo se torna ainda mais evidente quando se percebe que não é possível e nem favorecido um diálogo entre a Geografia Escolar e a Geografia Acadêmica, o que pressupõe uma competência por parte do professor relacionada à sua formação inicial, seu repertório cultural, seus canais de atualização e fundamentalmente um domínio linguístico e pedagógico dos conceitos científicos da ciência. É importante reforçar que essas exigências, essenciais para uma formação contínua na maioria das escolas, não fazem parte de suas prioridades, e são, muitas vezes, inacessíveis aos professores.

Acredita-se que com a realização desta pesquisa, estaremos contribuindo para o debate da educação, de modo geral, dentro do atual contexto nacional. Além de contribuirmos para a compreensão e assim a ampliação do papel da Geografia Escolar, como aquela que, devido às novas condições históricas, poderá auxiliar na construção de outra globalização, como fomentado pelo professor Milton Santos.

\section{METODOLOGIA}

Para a investigação, foi escolhida uma análise qualitativa que se mostrou mais interessante, devido aos métodos que serão utilizados para o recolhimento de dados observação das aulas, aplicação de questionário e aplicação de entrevistas semiestruturadas e para a análise - que será realizada com base na bibliografia previamente estudada.

O estudo se constitui em análise do cotidiano e das práticas e nas narrativas dos professores do ensino fundamental. Por isso a escolha da pesquisa qualitativa: "a pesquisa qualitativa se identifica com algumas técnicas, tais como a observação do participante, história ou relatos de vida, análise de conteúdo, entrevista não diretiva”, etc (GRUBITS; DARRAUT-HARRIS, 2004, p.111). Diante disso, acreditamos que esse tipo de pesquisa é a melhor opção para o nosso trabalho.

Inicialmente, foi realizado o trabalho de revisão bibliográfica sobre a Educação Geográfica para dar o embasamento necessário para a inicialização do trabalho de campo. Após a leitura e discussão sobre o tema o qual se destina a pesquisa, foi realizada uma delimitação do campo de estudo.

É importante destacar que apesar de as duas escolas serem públicas, uma localiza-se numa região periférica e a outra no centro da cidade, região economicamente mais abastada. 
A prática educativa do professor de geografia como ferramenta para a constituição da consciência cidadã

Esta pesquisa foi realizada junto de duas professoras da rede municipal da cidade de Cariacica-ES, tendo como fato primordial para tal escolha os diferentes contextos sociais. Utilizamos, no desenvolvimento da pesquisa, nomes fictícios, preservando de tal maneira a identidade das pessoas envolvidas e também e das escolas.

\section{A CONSCIÊNCIA ESPACIAL CIDADÃ}

Para Andreis (2009), o ensino de geografia vai além do que a mera reprodução burocrática de conteúdos tanto dos sistemas escolares quanto da escolha do próprio professor. Muitas vezes limitado ao uso de livros didáticos, o docente exprime os conteúdos e padrões temáticos trabalhados em sala de aula de modo mais geral, o que determina as diferentes formas que os alunos aprendem os conteúdos geográficos. Dessa forma, devem ser inseridos no contexto das mudanças e transformações pelas quais passam a sociedade, atribuindo significado às aprendizagens por parte do sujeito, culminando ou não na construção de uma consciência espacial e cidadã. Esta consciência de cidadania não será algo passível de doação ou transmissão, mas de um processo de construção e desenvolvimento que só será possível por meio de uma ação de busca desenvolvida e conquistada pelas análises e vivências do educando na escola.

Nesta perspectiva, pode-se compreender que o espaço geográfico e a geografia escolar são fundamentais para a vida e construção de uma consciência espacial e cidadã que compreende os movimentos articuladores presentes num espaço em constante transformação. Essa compreensão oportuniza o entendimento do lugar como constituinte e como resultado de complexas relações que se processam na constituição das paisagens, que são resultados de diferentes relações entre o local e o global. Para Andreis (2009), o fato de ser cidadão não se relaciona somente com os direitos e garantias proporcionados pelo Estado e seus territórios limítrofes, mas também com o caráter simbólico presente nas práticas que proporcionam a sensação de pertencimento.

A noção de cidadania envolve o sentido que se tem do lugar e do espaço, já que se trata da materialização das relações de todas as ordens, próximas ou distantes. Conhecer o espaço é conhecer a rede de relações à qual se está sujeito, da qual se é sujeito. Alienação do espaço e cidadania se configuram um antagonismo a considerar (ANDREIS, 2009, p. 20).

Assim, o ensino de Geografia e a construção de uma consciência espacial-cidadã devem estar em conformidade com a interpretação do espaço através dos múltiplos fatores intencionados que o condicionam e do qual o sujeito coparticipa nessa constante construção vivenciada pelo 
A prática educativa do professor de geografia como ferramenta para a constituição da consciência cidadã

cotidiano e apropriado sob a forma de lugar, como espaço de pertencimento do sujeito, mas que se relaciona com as diferentes escalas dos espaços. É exatamente esta a crítica que se faz a um ensino fragmentado e alienado dessa realidade concreta, uma vez que impossibilitaria o exercício da cidadania porque não seria capaz de reconhecer e interpretar as diferentes relações sociais que são personificadas pela concretude do espaço.

[...] a consciência espacial - cidadã é entendida como consciência das atitudes - ações individuais praticadas e produzidas socialmente, a partir de um saber - pensar o espaço com criatividade e comprometimento ético responsável - o que implica em desenvolvimento de valores (NOGUEIRA, 2009, p.79).

A constituição dessa consciência espacial-cidadã é descrita por Nogueira (2009) e é essencial para o entendimento do papel da Geografia para a construção, significação e importância da consciência dessa espacialidade. Nesse sentido, o autor afirma:

[...] a formação de uma consciência espacial - cidadã demanda que se pense e defenda os princípios jurídicos e políticos intrinsecamente relacionados a uma "ética da responsabilidade" (HANS JONAS, 1995) a uma tomada de consciência e atitudes que contribuam para os atores sociais se perceberem como tais e possam, a partir disso, agir em sociedade no plano local - global e global - local, tendo em vista a força do que significa. Comprometer-se responsavelmente com sua cultura, seu grupo social, sua comunidade, seu lugar de vivência (NOGUEIRA, 2009, p. 84).

É a partir dessa conscientização do espaço essencial para a construção crítica e reflexiva do sujeito, citada por Nogueira, que este defende sua posição como algo fundamental para a formação dessa consciência espacial - cidadã.

\section{AS PRÁTICAS DOS PROFESSORES}

Com o objetivo de tecer reflexões acerca das práticas das professoras, buscamos categorizar as observações das aulas, bem como as informações presentes nas entrevistas, organizadas do seguinte modo: a) perspectiva pedagógica da problematização do conteúdo e a dialogicidade; b) abordagem de conteúdo em torno da formação da consciência espacial cidadã, c) processo de ensino e de aprendizagem na conscientização espacial.

\section{A) PERSPECTIVA PEDAgógiCA DA PROBLEMATIZAÇÃo do CONTEÚdo E A DIALOGICIDADE}

A partir das falas das professoras, passamos para a análise das práticas docentes, que estão assentadas numa perspectiva que entende a problematização do conteúdo como 
A prática educativa do professor de geografia como ferramenta para a constituição da consciência cidadã

condição de libertação e de situação gnosiológica (FREIRE, 2011). Assim, podemos considerar que em sua prática, o professor deveria primar pelo desenvolvimento do conteúdo, uma vez que problematizando a realidade do aluno, esta lhe possibilitaria a compreensão da lógica dos arranjos espaciais, já que se trata do ensino de geografia.

As falas das professoras evidenciaram alguns aspectos relevantes a este respeito:

É o que eu te falei sobre a questão dos conteúdos dos livros didáticos. Por exemplo, está acontecendo algo na cidade dele, no estado em que ele vive, mas você está ali trabalhando uma coisa bem diferente, porque você tem que cumprir aquele conteúdo. Mas quem sabe é o professor, cada professor tem uma forma de trabalhar. Eu não sou muito boa nisso não. Mas eu acho muito interessante ver colegas que conseguem usar o jornal na sala de aula, trazer fatos do cotidiano e tentar aplicar, conciliar aquilo ali com o conteúdo que ele está trabalhando. Eu sou muito presa a essa questão do currículo, aquela coisa muito burocrática. É claro que na sala de aula sempre acontece alguma coisa, quando acontece um movimento político, quando saem nos jornais, sempre sai algum comentário. Mas no ensino fundamental é mais complicado. (Professora A - Entrevista realizada em 07/07/2019).

As falas indicam sobre a prática uma preocupação com o aspecto problematizador do conteúdo, no entanto, essa condição é sobreposta pela lógica burocrática da instituição e a própria práxis do educador, em sua dimensão política (FREIRE, 2011). Uma alternativa a essa condição da prática educativa é a própria reflexão sobre si que FREIRE (2011) indica como:

[...] o momento fundamental é o da reflexão crítica sobre a prática. É pensando criticamente a prática de hoje ou de ontem que se pode melhorar a próxima prática [...] e que essa reflexão possa possibilitar a compreensão dessa dimensão problematizadora como de grande importância para a formação de uma consciência espacial - cidadã (FREIRE, 2011, p. 40).

A possibilidade de pensarmos a educação como prática problematizadora nos permite, através da dialogicidade, transpor a relação vertical eu (professor) - tu (aluno), pois é no diálogo que ambos se encontram para a conquista do mundo (Freire, 2013).

Os referenciais didáticos normalmente são os noticiários de jornais, a imprensa falada e a imprensa escrita, eu acho importante o livro didático e o conhecimento que o aluno já traz consigo, a gente tem que elaborar, o aluno tem muito conhecimento, às vezes ele não sabe elaborar esse conhecimento, então a gente tem que ajudar ele a elaborar o conhecimento que ele tem. (Professora B - Entrevista realizada em 10/08/2019).

Novamente, percebe-se uma aproximação com a perspectiva da dialogicidade, pois ao considerar "o conhecimento que o aluno já traz consigo", entende-se que ele não é apenas um 
objeto sobre o qual o professor deve depositar seu saber (FREIRE, 2011, 2013). Dessa forma, ao dizer que o aluno tem conhecimento e que os professores precisam ajudá-lo em sua elaboração, esta fala, de uma das professoras entrevistadas, parece indicar que o conhecimento do aluno, apesar de ser visto como pensamento - linguagem que revela sua percepção da realidade (FREIRE, 2013) -, não é levado em consideração em todo o seu processo dialógico de construção do saber geográfico escolar.

O educador, no entanto, deve buscar nesse conhecimento a leitura de mundo que os educandos trazem consigo, bem como a relação entre esses saberes e o ensino dos conteúdos, neste caso de geografia, que tem relação com a dimensão espacial de sua existência. Assim, a fala de cada uma das professoras mostra que existe tanto uma concepção da educação problematizadora e dialógica, quanto uma aproximação dessas concepções em suas práticas educativas.

\section{B) A ABORDAGEM DE CONTEÚdOS ENTORNO DA FORMAÇÃO DA CONSCIÊNCIA ESPACIAL CIDADÃ}

A importância dos conteúdos é trabalhada por Freire (2011) como crucial para a formação crítica do aluno, na tomada de consciência do mundo e de si mesmo. Na visão do autor, os conteúdos programáticos devem ser produzidos a partir de um diálogo entre o educador e os educandos. Esses conteúdos precisariam partir da experiência dos alunos e daquilo que consideram importante. Esse conteúdo programático, adquirido através de um diálogo entre professor e aluno, originaria essa sistematização do que faz parte da vida dos alunos, do seu cotidiano, que é capaz de formar uma consciência espacial cidadã.

Quanto ao modelo educacional existente, Paganelli (2002) fala que a organização e o modo de abordar os conteúdos na educação geográfica estão associados à forma de como se pensa, organiza e planeja o currículo na educação básica.

Em relação aos conteúdos abordados no ensino de Geografia da educação básica, Campos (2005) nos dá uma visão do modelo que vem sendo trabalhado habitualmente nas escolas. Esse conteúdo encontra-se fragmentado em Geografia Física e Geografia Humana, sendo apresentado inicialmente a parte física. Esta visão fragmentada não permite um entendimento da totalidade, o que dificulta a percepção do mundo como ele é, algo único e não fragmentado. Para entender o espaço geográfico, é necessário a visualização e entendimento da totalidade e não apenas dos fragmentos. 
A prática educativa do professor de geografia como ferramenta para a constituição da consciência cidadã

No que tange ao ensino e aprendizagem de Geografia, Nogueira (2009) entende como crucial que sejam trabalhados conteúdos referentes ao espaço geográfico, paisagem, região, lugar, território, escala, natureza, sociedade e tempo. Ele entende que esses conceitos são capazes de construir um conhecimento crítico acerca do espaço geográfico.

O conteúdo de geografia que encontramos nas escolas é pré-moldado, criado de fora sem participação dos estudantes - e aparece citado pelas professoras entrevistadas que se dizem presas a ele, sem terem alternativas para mudanças. A professora " $A$ " se diz consciente da importância de trabalhar com alguns outros conteúdos fora daqueles abordados tradicionalmente pelo currículo da escola:

[...] tenho a visão de que acho que tem alguns conceitos que são mais importantes, mas nem sempre consigo trabalhar. Fico presa ao currículo e acabo trabalhando outros conteúdos. Eu gosto de trabalhar primeiro os conteúdos físicos e depois os humanos. E acho que os mais importantes são aqueles que envolvem a questão da população, a interação do homem e o espaço (Professora A - Entrevista realizada em 07/07/2019).

Com esta fala, é possível analisar que a professora tem consciência de que há coisas importantes para a formação e que não são abordadas no currículo tradicional, mas, como ela se vê atada à necessidade de trabalhar esses conteúdos moldados, acaba deixando os outros de lado: “[...] está acontecendo algo na cidade dele, no estado em que ele vive, mas você tá ali trabalhando uma coisa bem diferente, porque você tem que cumprir aquele conteúdo" (Professora A - Entrevista realizada em 07/07/2019).

Percebe-se também, através da fala dessa professora, que os conteúdos trabalhados com os alunos não levam em conta sua realidade, seu cotidiano, não estimulam a reflexão do educando acerca do seu lugar, etc. Como possibilitar a tomada da consciência espacial cidadã se o educando não é estimulado a pensar o seu lugar no mundo ou não é levado a refletir sobre este mundo e este lugar?

Percebemos também em sua fala o modelo de currículo que é elaborado para as escolas e que deve ser seguido pelos professores que são cobrados pelas instituições de ensino em que trabalham. Um currículo que determina as práticas e acaba estipulando um tempo para cada atividade.

Porém, Freire (1996) diz que ensinar também exige respeito aos saberes dos educandos, e que para isso, poderíamos trabalhar com coisas próximas aos alunos, partindo das experiências deles e dos lugares onde vivem. É perceptível também a questão da fragmentação da Geografia em Física e Humana, fator que dificulta a compreensão do espaço em sua totalidade, impedindo a formação do cidadão espacialmente consciente. $\mathrm{O}$ modelo que 
A prática educativa do professor de geografia como ferramenta para a constituição da consciência cidadã

prega essa dicotomia é a Geografia Tradicional, que primeiro deve constar uma descrição da superfície terrestre, e somente após isso, as falas referentes à economia, sociedade e outros temas.

Na mesma fala a professora A diz achar mais importantes os assuntos relacionados à população, à interação do homem e ao espaço. Ao se referir à população, entendemos que ela trata os aspectos mais descritivos da sociedade, como, por exemplo, os relacionados à demografia, natalidade, mortalidade etc, o que se constata em outro momento de sua fala:

[...] Conceito de geografia humana, no caso o conceito de população, é importante, porque ele faz parte dessa população, ele está inserido na população de um estado, país; noções de taxa de natalidade, mortalidade e outros são importantes para entender as diferenças entre os países, a própria ocupação, porque uns países são mais populosos e tem controle de natalidade (Professora A - Entrevista realizada em 07/07/2019).

Percebemos que durante as observações, entrevistas e exercícios aplicados pelas professoras, A e B, ambas trabalham com uma perspectiva mais tradicional de geografia. $\mathrm{O}$ fato é: a partir da visão de geografia das professoras, é possível formar cidadãos espacialmente conscientes? Isso é o que pretendemos analisar através das partes das entrevistas e observações de aulas que se seguem. A professora "A" admite trabalhar com uma Geografia Tradicional, ao falar:

Eu sou um pouco tradicionalista, Geografia Tradicional. Eu acabo adotando livros que tenham essa linha, por causa da questão conceitual, da esquematização do conteúdo, da sequência que traz. Eu não gosto daqueles livros que trazem aquele conteúdo tudo embaraçado, que não tem uma sequência muito boa (Professora A - Entrevista realizada em 07/07/2019).

Nesta fala, a docente afirma seguir a geografia tradicional corrente, que defende uma prática com enfoque conteudista, no qual os alunos são levados a aprender os conteúdos através do método de memorização, sendo trabalhados os assuntos que, na maioria das vezes, não fazem parte de suas vidas. Quanto à organização dos conteúdos nos livros didáticos, ela diz que prefere os livros que seguem uma linha mais tradicional, pois eles são mais organizados e têm uma divisão bem delimitada entre geografia física, economia e população.

$\mathrm{Na}$ visão da professora, os livros didáticos que trazem uma proposta que exclui a separação entre os conteúdos físicos e humanos - que prega o abandono da fragmentação - são "embaraçados", pois tratam ao mesmo tempo de assuntos que ela considera distintos. Já a professora "B" cita os conteúdos de geografia que entende como primordiais: Eu acho que primeiro de tudo ele tem que saber o que é 
Geografia. Sabendo o que é geografia, ele vai saber discernir a condição física do lugar, e entendendo a condição física, ele consegue fazer um... elaborar o contexto econômico, porque a condição física impõe a economia, quem mora no morro, no baixo, na beira do rio, quem mora na zona rural, na zona urbana... (Professora B - Entrevista realizada em 10/08/2019).

Nesta fala, percebemos que a professora acredita que as condições físicas do lugar determinam as outras, como a econômica, por exemplo. A partir dela, podemos perceber uma das correntes da Geografia Tradicional: o determinismo. Este modelo tradicional se confirma ao observar a metodologia de trabalho das professoras em sala, os exercícios, a exemplo dese que foi trabalhado pela professora $\mathrm{B}$, que passou um exercício de completar, no quadro, e pediu para os alunos - da turma de $8^{\circ}$ ano $\mathrm{A}$ - copiarem e responderem, com base em uma leitura do capítulo do livro.

\section{Exercício para completar:}

1) A América Platina Latina é constituída por três países, que são. Sendo que a. é o maior país da América Platina em extensão territorial. cuja capital é Montevidéu é o. que não tem saída para o mar.

A aula da Professora B se baseia em uma leitura do livro didático com os alunos. No decorrer da leitura, ela vai interrompendo para explicar algum conceito com o qual eles não estão familiarizados, e a aula vai seguindo assim, apenas com a leitura dos alunos e a explicação dos conceitos pela professora, sem debates ou questionamentos.

Com os exercícios e observação das aulas da professora A, pudemos perceber que ela trabalhou exercícios que não se aproximam da realidade dos alunos, os exercícios não foram discutidos, não houve nenhum tipo de problematização acerca do tema, os alunos não foram incentivados a falar. Ela mantém um foco no conteúdo oficial, com métodos avaliativos tradicionais:

Comoque eu trabalho? Eu trabalho o conteúdo, sempre estou passando exercício, cobrando caderno. O menino na sala de aula, a gente tem que ser realista, ele tem que estar ali com o caderno, fazendo o dever, se não ele vai ficar conversando na sala, bagunçando. Então, se eu não cobrar isso, fica bem difícil trabalhar (Professora A - Entrevistarealizada em 07/07/2019).

Com a fala da professora, foi possível perceber a situação da educação na atualidade. As dificuldades encontradas pelo professor são muitas. A professora faz um desabafo acerca 
A prática educativa do professor de geografia como ferramenta para a constituição da consciência cidadã

da dificuldade de trabalhar de outra forma que não a de cobrar o conteúdo de maneira tradicional. Diante disso, as professoras demonstram uma forma de trabalho no qual os alunos não têm participação na aula, não são estimulados a pensar, a debater. Como colocado pela professora A, o ideal para ela é que o aluno grave o conteúdo:

Ora, parece que a Geografia Tradicional não presta, agora é só a Geografia Crítica. Tudo bem, você tem que ter a Crítica, mas tem que ter a Tradicional também. Por que se não fica muito solto e ele não grava, ele não assimila, não entende (Professora A - Entrevista realizada em 07/07/2019).

A professora demonstra uma ideia disseminada na área educacional, de que o aluno bom é o que grava e decora os conteúdos, e assim, são capazes de repeti-los com propriedade. Isso provavelmente está ligado ao modelo de escola que temos, no qual professores e alunos são cobrados de várias maneiras, e o que importa é o resultado das provas, a média de alunos aprovados ao fim do ano e não a aquisição do saber.

A partir dos dados recolhidos, comprovamos como já dito, a perspectiva tradicional trabalhada pelas professoras A e B. Percebemos que os conteúdos ministrados por elas são retirados do livro didático e que elas seguem o modelo de distribuição de conteúdos relatado por Campos (2005). Esse modelo conteudista adotado, cujos ensinamentos priorizados são os que vêm moldados, sem o respeito pelo cotidiano dos educandos, dificulta o processo de conscientização desses alunos acerca do seu lugar. Dentro do que foi trabalhado pelos docentes, não se encontram assuntos ligados à realidade dos alunos ou àquilo que eles realmente consideram importantes; não encontramos bases capazes de propiciar a tomada de consciência acerca de si e do mundo, que Freire (1987) diz que só é possível através de uma educação problematizadora, que considere a experiência dos alunos.

\section{C) O PROCESSO DE ENSINO E DE APRENDIZAGEM NA CONSCIENTIZAÇÃO ESPACIAL CIDADÃ}

Para analisarmos este item, consideraremos primeiro o aspecto do ensino. Dessa forma, indicamos que estamos entendendo o ensino como ato em que "ensinar não é transferir conhecimento, mas criar as possibilidades para a sua produção ou sua construção" (FREIRE, 2011, p. 24).

O que pretendemos a partir desse ponto é identificar quais as estratégias e procedimentos metodológicos utilizados para que o ensino possa alcançar o objetivo da aprendizagem de uma conscientização espacial-cidadã. Em relação às estratégias de ensino e 
aprendizado analisadas nas falas dos professores, destaca-se uma grande importância dada ao conteúdo presente nos livros didáticos:

Sim, com certeza o livro didático é amplamente construtivo no que diz respeito a isso... Tipo, tem lá o assunto, o campo e a cidade, as diferentes formas de organizar o espaço, o aluno aprende a ser cidadão, o aluno aprende a respeitar aqui, aprende a respeitar lá, então eu acho o livro, que o livro de geografia ajuda muito na construção do cidadão. (Professora B Entrevista realizada em 10/08/2009).

[...] eu trabalhei muito com o Projeto Araribá, o currículo de Cariacica é muito baseado nesse livro. Ele está esquematizado de uma forma que dá para trabalhar legal. Agora, têm livros que realmente você acaba tendo que lançar mão de outros materiais, outros métodos, porque o livro não ajuda. Eu vejo que os livros, hoje, carecem daquele conteúdo um pouco tradicional, que é o conceito. Tem muito livro que falta o conceito. Por exemplo: você vai trabalhar Clima. Tem que ter o conceito de clima. Têm livros que não trazem essa parte tradicional. Ora, parece que a Geografia Tradicional não presta, agora é só a Geografia Crítica. Tudo bem, você tem que ter a Crítica, mas tem que ter a Tradicional também. Porque se não fica muito solto e ele não grava, ele não assimila, não entende. Eu acho que, hoje, nos livros está faltando essa parte conceitual (Professora A - Entrevista realizada em 07/07/2019).

Portanto, a orientação do conteúdo para a construção do saber geográfico está associada à perspectiva proposta nos livros didáticos. Esse é um ponto problemático em dois aspectos: em primeiro lugar, pelo seu caráter transmissor (FREIRE, 2011, 2013); em segundo, pela tendência homogênea dos conteúdos. O primeiro aspecto, o caráter transmissor do livro didático, tem como princípio o desenvolvimento do texto didático, sem levar em consideração a realidade geográfica dos alunos. É nesse contexto que a dimensão crítica da prática educativa se evidencia:

Um professor, sujeito desse conhecimento e não simples transmissor, é capaz de enfrentar, com êxito, a seleção de conteúdos e sua organização em um planejamento curricular. É capaz de situar-se crítica e criativamente diante das concepções e elaborações dos autores, nas diferentes publicações e em relação aos materiais didáticos disponibilizados pela indústria cultural (PAGANELLI, 2013, p. 150).

Sobre esse segundo aspecto, a tendência homogênea dos conteúdos, CALLAI (2001) alerta que:

Um programa oficial pronto e organizado para se adequar/aplicar em todas as escolas, passa por cima das contradições existentes na sociedade de um modo mais amplo, e da diversidade que existe nos níveis regionais. Supõe uma sociedade harmônica e homogênea e desconhece/despreza as contradições regionalizadas e localizadas. É, sem dúvida, um instrumento de poder e como tal funciona ideologicamente no sentido de se perceber/ reconhecer apenas os problemas mais gerais, sem considerar a realidade 
concreta em que vivem os alunos e mesmo os professores (CALLAI, 2001, p.135).

A questão central que se coloca é em que medida esse conteúdo, que tem como base o livro didático, pode contribuir para o ensino e a aprendizagem em geografia, na perspectiva da consciência espacial cidadã? Qual enfoque teórico-metodológico da geografia o livro utiliza? Podemos perceber que a Professora A manifesta certo princípio teórico metodológico que orientaria sua prática pedagógica, no que se refere ao ensino aprendizagem em geografia, ao afirmar que:

[...] têm livros que realmente você acaba tendo que lançar mão de outros materiais, outros métodos, porque o livro não ajuda. Eu vejo que os livros, hoje, carecem daquele conteúdo um pouco tradicional, que é o conceito. Tem muito livro que falta o conceito. Por exemplo, você vai trabalhar Clima, tem que ter o conceito de clima... (Professora A - Entrevista realizada em 07/07/2019).

A preocupação dessa professora indica sua atenção dada aos conceitos da geografia que ela busca a partir dos livros didáticos. Porém, as estratégias de ensino permanecem dependentes dos livros didáticos, e somente quando não há condições de seguir este modelo é que existe a busca por outros procedimentos de ensino e de aprendizagem.

Isso revela, ainda, a ausência de um olhar espacial como método da geografia para estudarmos a realidade (CALLAI, 2012) que dialoga com a situacionalidade do aluno como alternativa para a problematização do conteúdo (FREIRE, 2013). O processo de ensino e de aprendizagem da conscientização espacial-cidadã parte do livro didático com suas características transmissoras e homogêneas dos conteúdos, conforme afirma a Professora B: “então eu acho o livro, que o livro de geografia ajuda muito na construção do cidadão".

A partir da observação das aulas, outro elemento se coloca para análise, trata-se dos procedimentos metodológicos referentes ao ensino e aprendizado do saber geográfico. Como destacado, anteriormente, as observações mostraram uma grande dependência em relação ao livro didático. No entanto, as falas das professoras mostraram experiências com outras estratégias, por exemplo, aula de campo e atividades em grupo.

A comunidade contribui muito quando ela é convidada, então, quando o aluno desenvolve um projeto que a escola participa, até a disciplina da escola muda; quando o projeto fica só dentro da escola, a comunidade não está inserida dentro do contexto, aquele projeto, quando acaba, parece que acabou tudo; quando a comunidade vem, aquele projeto se perpetua dentro da escola, se a gente faz um projeto para desenvolver... tipo ano passado, eu 
fiz um projeto viajando pelo mundo. Aí a comunidade veio e todo mundo pegou o livro informativo, como os pais viram aquilo, os alunos ficaram entusiasmadíssimos. Então, aquilo gerou uma conversa, um diálogo, então a comunidade participou, se a comunidade não vem, se a coisa fica só dentro da escola, quando acaba o projeto, acabou tudo, no outro dia já não tem mais nada. Então a comunidade é importante para o desenvolvimento tanto do aluno como da aula, ajuda muito. A comunidade é muito importante (Professora B - Entrevista realizada em 10/08/2019).

[...] mas sempre tem projetos na escola que acabam ajudando esses tipos de conteúdos. Nos projetos, você pode trabalhar de forma interdisciplinar, pode fugir um pouco daquele conteúdo exigido no currículo. Porque o Estado tem o currículo, a prefeitura está adotando... E você nem sempre consegue fazer isso (trabalhar outros conteúdos). Você tem que seguir (o currículo). Você pode fugir um pouquinho e as brechas que a gente tem são os projetos (Professora A - Entrevista realizada em 07/07/2019).

Sobre esses aspectos, referentes às estratégias de ensino e de aprendizado, CALLAI (2012) orienta que:

O processo de ensino-aprendizagem supõe um determinado conteúdo e certos métodos. Porém, acima de tudo, é fundamental que se considere que a aprendizagem é um processo do aluno, e as ações que se sucedem devem necessariamente ser dirigidas à construção do conhecimento por esse sujeito ativo (CALLAI, 2012, p. 79).

Portanto, os procedimentos metodológicos do ensino e da aprendizagem devem intencionar a aprendizagem do aluno enquanto processo dialógico. É sobre essa perspectiva de compreensão dos procedimentos metodológicos do ensino e da aprendizagem que, ao analisarmos as observações e as falas dos professores, podemos constatar certo distanciamento entre o discurso e a prática, pois, apesar do reconhecimento da importância de outras metodologias - além do livro didático -, as observações das aulas revelam a utilização do livro didático como parâmetro de trabalho.

Há uma crescente literatura que expõe alternativas metodológicas para o desenvolvimento na prática educativa do ensino de geografia (CALLAI, 1999, 2011, 2012; CAVALCANTI, 2010). A questão que se coloca é que a consciência espacial cidadã está diretamente associada a uma conscientização espacial da existência dos alunos e do seu entorno geográfico. Diante de tal conscientização, evidenciam-se as contradições da realidade, seus processos de constituição, o que nos impele a dimensão política da realidade, ou seja, nossa dimensão cidadã.

O que se revela das observações de campo, sobre os processos de ensino e de aprendizagem, é o entendimento da conscientização espacial cidadã como algo que se 
A prática educativa do professor de geografia como ferramenta para a constituição da consciência cidadã

desenvolveria a partir do livro didático, em que a situacionalidade, como problematização do aluno (FREIRE, 2013) para a sua conscientização das relações espaciais, é, em poucos momentos, levado em conta.

\section{CONSIDERAÇÕES FINAIS}

Percebemos, através das análises dos dados recolhidos durante a pesquisa de campo, que existe de forma sutil uma intencionalidade por parte das professoras entrevistadas. Tal intencionalidade aparece, com mais clareza, na concepção de Geografia Escolar e na Perspectiva Pedagógica. Intencionalidade que se aproxima daquela defendida pelo presente trabalho a respeito da finalidade da Geografia na escola, qual seja, a formação da consciência espacial-cidadã. A partir dos indícios apresentados, fica evidente a necessidade de revisão das práticas nas aulas de Geografia, já que considerando a forma como os conceitos vêm sendo trabalhados, eles pouco contribuem para o processo de constituição de uma consciência crítica acerca da formação do Espaço Geográfico, entendido como a concretude das relações sociais que se expressam nas paisagens sempre em constante construção.

É de fundamental importância destacar as possibilidades políticas da resposta encontrada pelo presente trabalho. Dentro dessa gama quase infinita de possibilidades, pretende-se destacar o papel da Geografia na escola. Quando se fala em relações contraditórias, se fala tanto em imposição da estrutura quanto na produção da resistência. Como a Geografia, enquanto disciplina responsável pelo estudo do espaço geográfico, pode auxiliar nesse processo? A resposta para tal questão não é o objetivo imediato deste trabalho. O que se pretende, é indicar a importância de tal reflexão sobre as práticas dos professores de Geografia. Um caminho, talvez, seria seguir a fala de umas das professoras entrevistadas, que ao ser questionado sobre a importância da Geografia na escola, disse que "precisamos saber onde estamos".

\section{REFERÊNCIAS}

ANDREIS, A. M. Da informação ao conhecimento: cotidiano, lugar e paisagem na significação das aprendizagens geográficas na educação básica. Dissertação de Mestrado apresentado ao Programa de Pós-Graduação em Geografia da Universidade Regional do Regional do Noroeste do Estado do Rio Grande do Sul, Rio Grande do Sul - Ijuí, 2009.

CALLAI, Helena Copetti. Estudar o lugar para compreender o mundo. In: Ensino de geografia: práticas e textualizações no cotidiano, Castro Giovanni, Antônio Carlos (Org.), 2011. 10. Ed. Porto Alegre: Meditação, 2012.

CALLAI, Helena Copetti. A Geografia escolar e os conteúdos da Geografia. Anekumene, v. 1, p. 128-139, 2011. 
A prática educativa do professor de geografia como ferramenta para a constituição da consciência cidadã

CALLAI, Helena Copetti. A Geografia e a Escola: muda a Geografia? Muda o ensino? Terra Livre, São Paulo, n.16, p. 133-152, 2001.

CALLAI, Helena Copetti. O estudo do lugar como processo de pesquisa para a aprendizagem. Espaços da Escola, Ijui-RS, v. 31, p. 43-52, 1999.

CAMPOS, Eduardo. O contexto espacial e o currículo de geografia no Ensino Médio: um estudo em Ilha Bela- SP. Dissertação de Mestrado aprsentado ao Programa de Pós-Graduação em Geografia da Faculdade de Educação da Universidade de São Paulo, São Paulo, 2005.

CAVALCANTI, Lana de Souza. Concepções teórico-metodológicas da geografia escolar no mundo contemporâneo e abordagens no ensino. In: SANTOS. L. L. C. P. et al (Org.) Convergências e tensões no campo da formação e do trabalho docente. Belo Horizonte: Autêntica, 2010. p. 368 - 391.

FREIRE, Paulo. Educação como prática da liberdade. 14 ed. RJ: Paz e Terra, 2011.

FREIRE, Paulo. Pedagogia da autonomia: saberes necessários à prática educativa. 33. Ed. São Paulo: Paz e Terra, 2011.

FREIRE, Paulo. Pedagogia do oprimido. 54. Ed. RJ: Paz e Terra, 2013.

GRUBITS, Sonia; NORIEGA, José Angel Vera. Método Qualitativo: epistemologia, complementaridades e campos de aplicação. São Paulo: Vetor, 2004.

NOGUEIRA, Valdir. Educação Geográfica e formação da consciência espacial-cidadã no ensino fundamental: sujeitos, saberes e práticas. Tese de Doutorado apresentado ao Departamento de Educação da Universidade Federal do Paraná, 2009.

PAGANELLI, Tomoko Iyda. Reflexões sobre categorias, conceitos e conteúdos geográficos: seleção e organização. In: PONTUSCHKA, Nídia Nacib; OLIVEIRA, Ariovaldo Umbelino de. Geografia em Perspectiva: ensino e pesquisa. 4. Ed. São Paulo: Contexto, 2013. p. 149157.

SPEGIORIN, Mônica de Toledo e Silva. Por Uma Outra Geografia Escolar: prescrito e o realizado na atividade de ensino aprendizagem da Geografia. Dissertação de Mestrado apresentado ao Programa de Pós-Graduação da Pontifícia Universidade Católica de São Paulo, p.204, São Paulo - SP, 2007.

Artigo recebido em: 08 de setembro de 2020.

Artigo aceito em: 23 de dezembro de 2020.

Artigo publicado em: 05 de janeiro de 2021. 